\title{
Badania wpływu głównych parametrów napawania plazmowego na geometrię napoin w oparciu o metody planowania eksperymentu
}

\author{
Study of the effect of the main parameters \\ of plasma surfacing on the geometry of the welds overlays \\ based on the design of experiment method
}

\section{Streszczenie}

$\mathrm{Na}$ podstawie metod planowania eksperymentu analizowano wpływ podstawowych parametrów napawania plazmowego na wielkości opisujące geometrię napoin. Badania te wykonano dla układu: stal niestopowa typu S235JR - napoina na bazie Ni. Powłoki wykonano dla różnych wartości energii liniowej. W efekcie matematycznego opracowania wyników badań ustalono wpływ badanych parametrów na geometrię powłok i udział metalu podłoża w napoinie. Wykazano, iż jest różny wpływ analizowanych parametrów procesu napawania na mierzone wielkości.

Słowa kluczowe: napawanie plazmowe; napoina; planowanie eksperymentu

\begin{abstract}
The influence of the main parameters of plasma powder transferred arc welding on the geometry of the weld overlays is presented in the paper based on the Design of Experiment methods. These studies were performed for plain steel S235JR grade - Ni based overlay system. The coatings were made for different values of heat input. After mathematical processing of results, the effect of welding parameters onto overlays geometry and dilution level was determined. It was shown that particular surfacing parameters have different impact onto measured values.
\end{abstract}

Keywords: plasma surfacing; weld overlays; design of experiment

\section{Wstęp}

Napawanie plazmowe proszkowe ze względu na liczne zalety jest szeroko stosowane w modyfikacji bądź regene-

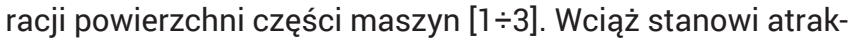
cyjną alternatywę dla znacznie droższych procesów napawania laserowego czy wiązką elektronów. Zastosowanie materiału dodatkowego w postaci proszku umożliwia otrzymywanie napoin o szerokim zakresie składu chemicznego

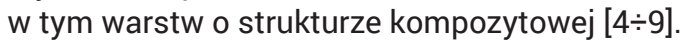

Jedną z cech charakterystycznych tego procesu jest duża liczba parametrów nastawczych. Z jednej strony umożliwia to otrzymywanie ściegów o różnych wariantach wymiarów geometrycznych, tj. bardzo wąskich i o małym nadlewie do bardzo szerokich o stosunkowo dużej wysokości. Z drugiej strony istnieje trudność w doborze parametrów warunkujących otrzymywanie powłok o pożądanych wymiarach i odpowiednio małym udziale metalu podłoża w napoinie. Toteż w celu ustalenia warunków napawania niezbędne jest wykonanie prób wstępnych. Natomiast badania wstępne wiążą się z dodatkowymi kosztami i wzrostem pracochłonności. Testy wstępne można znacząco ograniczyć dysponując odpowiednią praktyczną wiedzą inżynierską, która dodatkowo może być wspierana metodami planowania eksperymentu (ang. DOE Design of Experiments).

Korzyści wynikające z zastosowania statystycznych metod planowania eksperymentów omawiane są często zarówno w krajowej [10 $\div$ 13], jak i anglojęzycznej literaturze

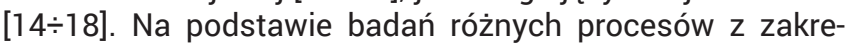
su inżynierii spajania wykazano liczne zalety wynikające z zastosowania narzędzi statystycznych.

W niniejszej pracy, stanowiącej kontynuację wcześniejszego cyklu badań [19], w oparciu o metody planowania eksperymentu, przedstawiono wpływ głównych parametrów napawania plazmowego komercyjnym proszkiem na bazie Ni na wymiary geometryczne i udział metalu podłoża w napoinie.

Dr inż. Mariusz Bober - Zakład Inżynierii Spajania, Politechnika Warszawska.

Autor korespondencyjny/Corresponding author: mbober@wip.pw.edu.pl 


\section{Stosowane materiały}

Do eksperymentu napawania zastosowano komercyjny proszek na bazie $\mathrm{Ni}$, który wg danych producenta zawiera dodatkowo: Si $2,5 \%$, B $1,4 \%$, Fe $\leq 1 \%$ oraz C $\leq 0,05 \%$. Ziarnistość tego proszku zawierała się w przedziale $50 \div 150 \mu \mathrm{m}$.

Napoiny wykonano na podłożach ze stali niestopowej o oznaczeniu S235JR. Do badań przygotowano próbki o wymiarach $10 \times 50 \times 150 \mathrm{~mm}$. Przed procesem napawania powierzchnia stalowych podłoży była czyszczona poprzez piaskowanie i odtłuszczana.

Przed wykonaniem właściwej serii prób przeprowadzono badania wstępne mające na celu określenie pozostałych, stałych parametrów procesu.

\section{Metodyka badań}

\section{Parametry procesu}

Na podstawie literatury [20] i wcześniej prowadzonych badań $[19,21,22]$ przyjęto natężenie prądu łuku głównego i prędkość napawania jako parametry zmienne. Sterowanie tymi parametrami decyduje o wartości energii liniowej procesu napawania, a więc istotnie wpływa na geometrię napoin. Zakres zmienności natężenia prądu przyjęto $\mathrm{w}$ przedziale $60 \div 140 \mathrm{~A}$ natomiast prędkości napawania $50 \div 70 \mathrm{~mm} / \mathrm{min}$. Pozostałe parametry procesu napawania były ustalone na stałym poziomie i niezmieniane $w$ trakcie napawania (tabl. I).

Tablica I. Parametry napawania plazmowego

Table I. Plasma surfacing parameters

\begin{tabular}{|l|c|}
\hline \multicolumn{1}{|c|}{ Parametr } & Wartość \\
\hline natężenie prądu łuku wewnętrznego & $40 \mathrm{~A}$ \\
napięcie łuku plazmowego & $25 \mathrm{~V}$ \\
wydatek proszku & $6 \mathrm{~g} / \mathrm{min}$ \\
wydatek gazu (argon N5.0): & $1,5 \mathrm{l} / \mathrm{min}$ \\
• plazmotwórczego & $8 \mathrm{I} / \mathrm{min}$ \\
• osłonowego & $5 \mathrm{I} / \mathrm{min}$ \\
• transportującego & $8 \mathrm{~mm}$ \\
amplituda oscylacji & $450 \mathrm{~mm} / \mathrm{min}$ \\
prędkość ruchu oscylacyjnego & $15 \mathrm{~mm}$ \\
odległość plazmotronu od przedmiotu & $4 \mathrm{~mm}$ \\
napawanego & \\
średnica dyszy zwężającej &
\end{tabular}

\section{Identyfikacja wielkości geometrycznych napoin}

Jako wielkości wyjściowe przyjęto wymiary charakteryzujące zarys geometryczny napoiny (rys. 1), którymi są:

- wysokość nadlewu a,

- szerokość lica b,

- głębokość wtopienia c = x - a,

- udział materiału podłoża $W$ napoinie $D$ wyznaczany ze wzoru: $\mathrm{D}=\mathrm{B} /(\mathrm{A}+\mathrm{B}) \times 100 \%$.

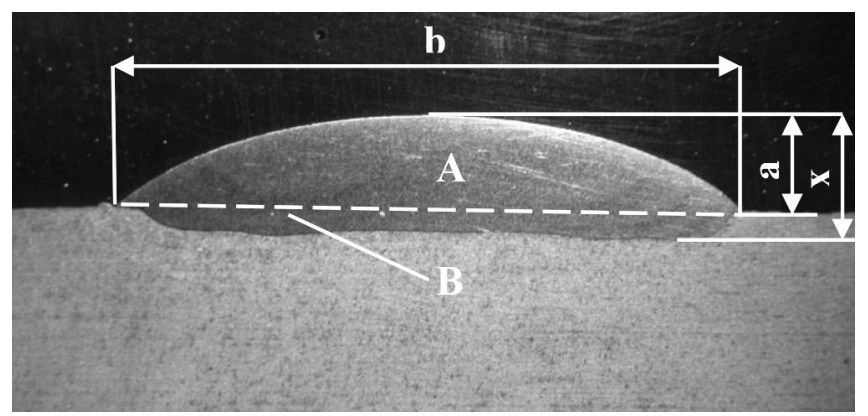

Rys. 1. Charakterystyczne wymiary geometryczne napoin

Fig. 1. The characteristic geometric dimensions of the weld overlays
Wybór planu eksperymentu

i opracowanie matrycy doświadczeń

Przyjęte zmienne wejściowe (parametry procesu) oraz możliwość ich dyskretnego sterowania determinują wybór odpowiedniego planu. W badaniach technologicznych najczęściej stosuje się plany, w których parametry ustawiane są na niewielu jednakowo od siebie odległych poziomach. Do najczęściej stosowanych planów tego typu należą plany statyczne dwupoziomowe lub trójpoziomowe. Pierwszą grupę planów charakteryzuje minimalna ilość doświadczeń oraz łatwość matematycznego opracowania, a model matematyczny badanego procesu ma postać liniową. Wadą planów dwupoziomowych jest mała informacyjność. Natomiast procesy, w których przybliżenie liniowe jest niewystarczające znacznie lepiej jest charakteryzować zależnościami drugiego stopnia, co umożliwiają plany trójpoziomowe. Wówczas opracowany model matematyczny procesu ma postać wielomianu drugiego stopnia, a więc można określić ekstremum badanej funkcji [23]. W związku z tym do realizacji eksperymentu przyjęto plan statyczny trójpoziomowy kompletny.

Według przyjętego planu czynniki wejściowe występują na trzech poziomach zmienności, tj. wyższym - oznaczanym +1 , średnim - oznaczanym 0 i niższym - oznaczanym - 1 . Matrycę eksperymentu przedstawiono w tablicy II. Zmienna $\mathrm{X}_{1}$ odpowiada parametrowi prędkości napawania, natomiast poprzez $\mathrm{X}_{2}$ oznaczono natężenie prądu.

Tablica II. Matryca planowania eksperymentu

Table II. Matrix design of experiment

\begin{tabular}{|c|c|c|c|c|}
\hline $\begin{array}{c}\text { Nr } \\
\text { próby }\end{array}$ & $\mathbf{X}_{1}$ & $\mathbf{X}_{2}$ & $\begin{array}{c}\text { Prędkość } \\
\text { napawania } \\
\mathbf{V}_{\mathbf{n}} \text { [mm/min] }\end{array}$ & $\begin{array}{c}\text { Natężenie } \\
\text { prądu } \\
\text { [ [A] }\end{array}$ \\
\hline 1 & +1 & +1 & 70 & 140 \\
\hline 2 & +1 & 0 & 70 & 100 \\
\hline 3 & +1 & -1 & 70 & 60 \\
\hline 4 & 0 & +1 & 60 & 140 \\
\hline 5 & 0 & 0 & 60 & 100 \\
\hline 6 & 0 & -1 & 60 & 140 \\
\hline 7 & -1 & +1 & 50 & 100 \\
\hline 8 & -1 & 0 & 50 & 60 \\
\hline 9 & -1 & -1 & 50 & 60 \\
\hline
\end{tabular}

\section{Wykonanie napoin}

Próby napawania plazmowego prowadzono przy użyciu urządzenia PTA 301 Control M firmy Hettiger Stellite GmbH. Napoiny wykonano zgodnie z parametrami zamieszczonymi w tablicach I i II. Długość napoin wynosiła ok. $120 \mathrm{~mm}$. Proces napawania prowadzono bez podgrzewania wstępnego.

\section{Badania napoin}

Po procesie napawania próbki przygotowano do badań mikroskopowych. W tym celu każda napoina został przecięta w płaszczyźnie prostopadłej do lica i równej odległości od początku ściegu, tj. $30 \mathrm{~mm}$. Następnie próbki przygotowano wg standardowej procedury.

Na rysunku 2 przedstawiono widok napoin. Widoczne są wyraźne różnice kształtu poszczególnych powłok. Wymiary opisujące geometrię napoin wyznaczano na stanowisku 

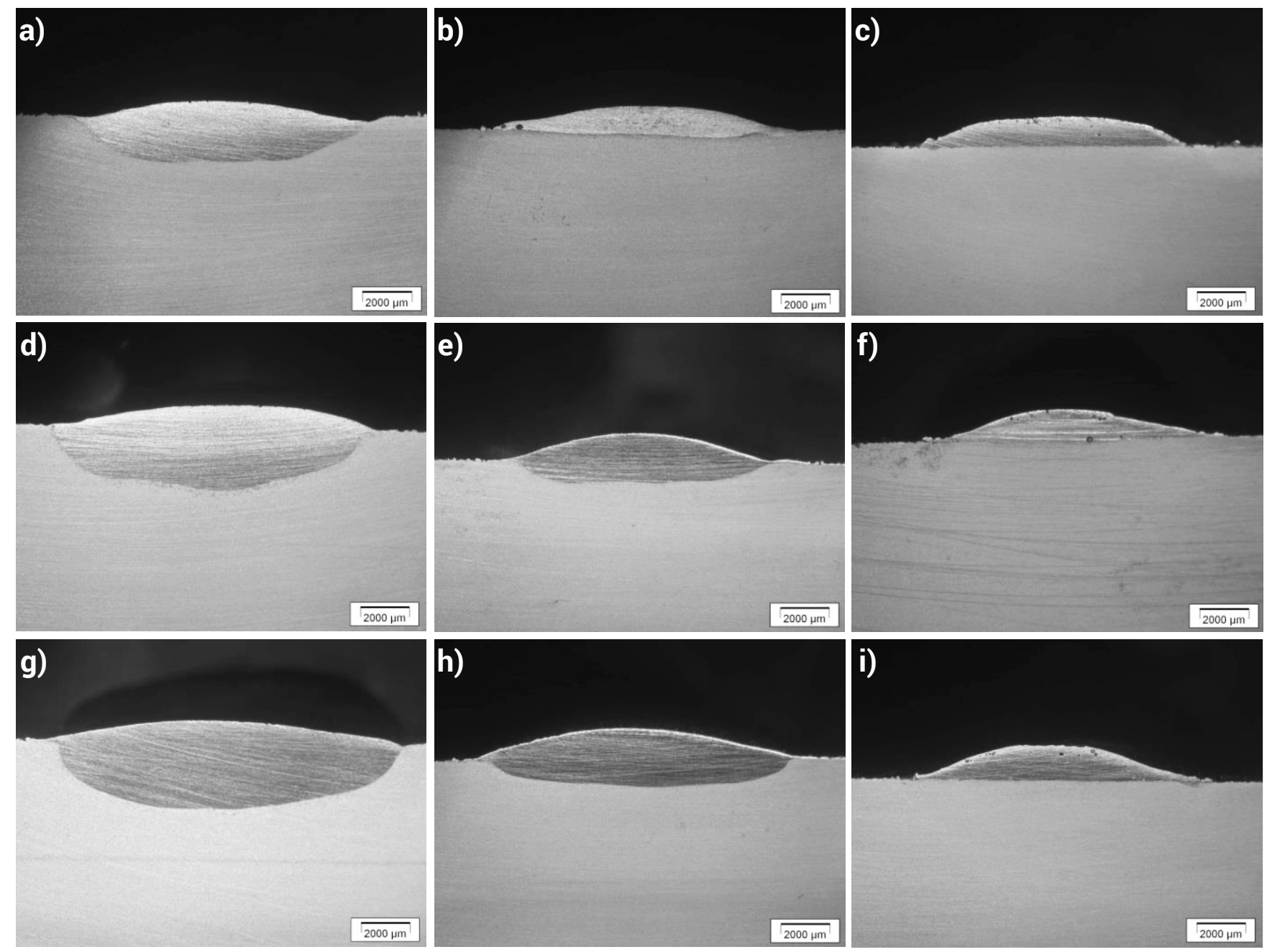

Rys. 2. Makrostruktury napoin

Fig. 2. The macrostructures of the welds overlays

wyposażonym w mikroskop stereoskopowy Olympus SZ40 z cyfrowym zapisem obrazu. Za pomocą programu komputerowego Olympus DP-Soft wyznaczano charakterystyczne wymiary napoin (rys. 1). Każdy pomiar powtarzany był trzykrotnie. W tablicy III przedstawiono zbiorcze wyniki pomiarów. Są to wartości średnie otrzymane z trzech równoległych pomiarów.

Tablica III. Wyniki pomiarów geometrii i udziału metalu podłoża w napoinie

Table III. The results of geometry measurement of welds overlays and dilution level

\begin{tabular}{|c|c|c|c|c|c|c|}
\hline \multirow{2}{*}{$\begin{array}{c}\mathrm{Nr} \\
\text { próby }\end{array}$} & \multicolumn{2}{|c|}{$\begin{array}{c}\text { Matryca } \\
\text { planowania } \\
\text { eksperymentu }\end{array}$} & \multicolumn{3}{|c|}{$\begin{array}{l}\text { Wymiary geometryczne } \\
\text { napoin [mm] }\end{array}$} & \multirow{2}{*}{$\begin{array}{c}\text { Udział } \\
\text { metalu } \\
\text { podłoża } \\
\text { w } \\
\text { napoinie } \\
\text { D [\%] }\end{array}$} \\
\hline & $x_{1}$ & $x_{2}$ & b & a & c & \\
\hline 1 (a) & +1 & +1 & 12,68 & 0,60 & 1,87 & 75,52 \\
\hline 2 (b) & +1 & 0 & 12,33 & 0,97 & 0,30 & 20,67 \\
\hline 3 (c) & +1 & -1 & 10,90 & 1,19 & 0,04 & 2,12 \\
\hline $4(d)$ & 0 & +1 & 13,26 & 0,91 & 2,54 & 75,43 \\
\hline $5(\mathrm{e})$ & 0 & 0 & 11,15 & 1,15 & 0,87 & 47,33 \\
\hline $6(f)$ & 0 & -1 & 11,99 & 1,19 & 0,14 & 6,80 \\
\hline $7(\mathrm{~g})$ & -1 & +1 & 14,86 & 0,83 & 2,72 & 77,81 \\
\hline $8(h)$ & -1 & 0 & 13,29 & 1,21 & 1,13 & 50,63 \\
\hline 9 (i) & -1 & -1 & 12,18 & 1,43 & 0,04 & 1,17 \\
\hline
\end{tabular}

\section{Matematyczne opracowanie wyników badań}

Model matematyczny procesu napawania $\mathrm{w}$ postaci wielomianu drugiego stopnia (1) wyznaczono wg metodyki przedstawionej w [23]:

$$
y=b_{0}+b_{1} x_{1}+b_{2} x_{2}+b_{11} x_{1}^{2}+b_{22} x_{2}^{2}+b_{12} x_{1} x_{2}
$$

gdzie: $b_{0}, b_{1}, b_{2}, b_{11}, b_{22}, b_{12}$ - współczynniki równania regresji.

Wstępne kodowanie czynników wejściowych $\mathrm{x}_{\mathrm{k}}$ dokonano wg następującego równania:

$$
\mathrm{X}_{\mathrm{k}}=\left(\overline{\mathrm{X}}_{\mathrm{k}}-\overline{\mathrm{X}}_{\mathrm{kO}}\right) /\left(\Delta \overline{\mathrm{X}}_{\mathrm{k}}\right)
$$

gdzie:

$\overline{\mathrm{X}}_{\mathrm{k}}$ - zakodowana postać k-tego czynnika wejściowego,

$\bar{X}_{k 0}-$ wartość centralna k-tego czynnika: $\bar{x}_{k 0}=\left(\bar{x}_{k \max }+\bar{x}_{k \min }\right) / 2$, $\Delta \overline{\mathrm{X}}_{\mathrm{k}}-$ zakres zmienności k-tego czynnika: $\Delta \overline{\mathrm{X}}_{\mathrm{k}}=\left(\overline{\mathrm{X}}_{\mathrm{kmax}}-\overline{\mathrm{X}}_{\mathrm{kmin}}\right) / 2$.

Po zakodowaniu czynników wejściowych (parametrów procesu) otrzymano:

$$
\mathrm{X}_{1}=\left(\mathrm{V}_{\mathrm{n}}-60\right) / 10 \quad \text { oraz } \quad \mathrm{x}_{2}=(\mathrm{I}-100) / 40
$$

Zgodnie z przyjętą metodyką, po wyznaczeniu współczynników regresji i ocenie ich istotności na przyjętym poziomie ufności $a=0,05$ otrzymano równania regresji $\mathrm{w}$ postaci zakodowanej wpływu parametrów napawania na geometrię i udział metalu podłoża w napoinie (tabl. IV). 
Tablica IV. Równania regresji wpływu czynników wejściowych na wielkości wyjściowe Table IV. The regression equations impact of input factors on the of output

\begin{tabular}{|c|c|}
\hline Czynniki wyjściowe & Postać równania regresji \\
\hline Szerokość napoiny (b) & $y=11,876-0,738 x_{1}+0,954 x_{2}+0,572 x_{1}{ }^{2}+0,387 x_{2}{ }^{2}-0,228 x_{1} x_{2}$ \\
\hline Wysokość nadlewu (a) & $y=1,142-0,119 x_{1}+0,246 x_{2}+0,044 x_{1}{ }^{2}+0,088 x_{2}{ }^{2}$ \\
\hline Głębokość wtopienia (c) & $y=0,877-0,28 x_{1}+1,152 x_{2}+0,164 x_{1}{ }^{2}+0,457 x_{2}{ }^{2}-0,212 x_{1} x_{2}$ \\
\hline Udział metalu podłoża w napoinie (D) & $y=42,011-5,216 x_{1}+36,447 x_{2}+5,203 x_{1}{ }^{2}+0,266 x_{2}{ }^{2}-0,808 x_{1} x_{2}$ \\
\hline gdzie: $x_{1}-$ prędkość napawania, $x_{2}-$ natężenie prądu \\
\hline
\end{tabular}

\section{Omówienie wyników badań}

Opracowane równania regresji umożliwiają ocenę wpływu natężenia prądu łuku głównego oraz prędkości napawania na wielkości geometryczne napoin oraz ich stopień rozcieńczenia materiałem podłoża (tabl. IV). Rzeczywiste wartości badanych wskaźników można wyznaczyć z równań w postaci odkodowanej, zastępując zmienne $\mathrm{x}_{1}$ i $\mathrm{x}_{2}$ odpowiednimi równaniami (3). Należy przy tym zaznaczyć, iż równania te są adekwatne w przyjętym przedziale zmienności czynników wejściowych.

Ponadto, można oszacować wpływ jednego z badanych czynników zmiennych na wartość wyjściową przyjmując drugi czynnik zmienny na stałym poziomie - rysunek 3 . I tak szerokość napoin zwiększa się stopniowo wraz ze wzrostem natężenia prądu łuku głównego (rys. 3a).

a)

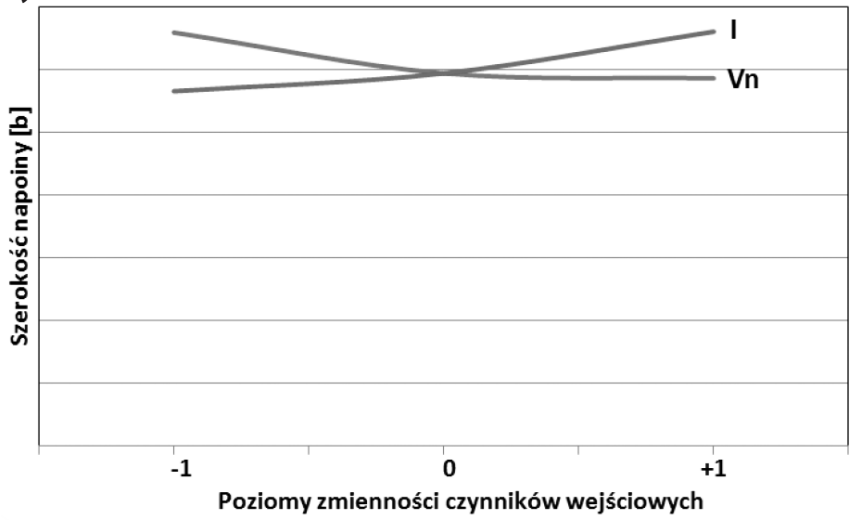

c)

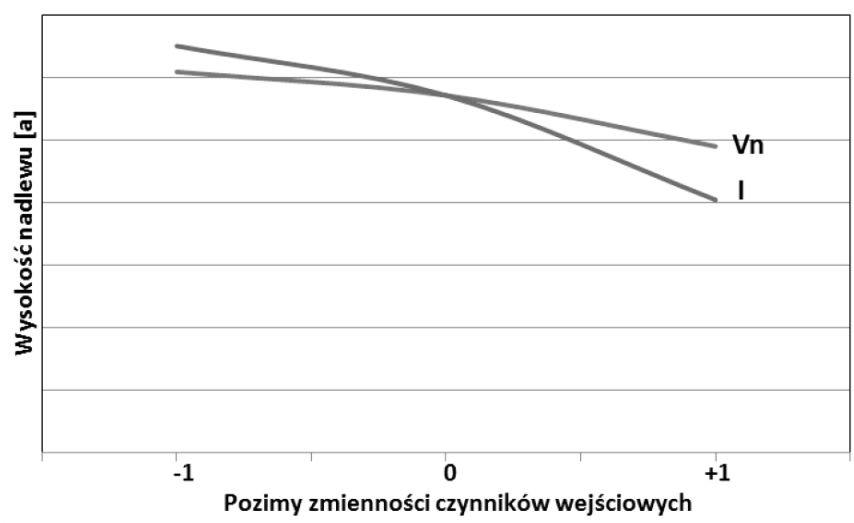

Zwiększanie natężenia prądu powoduje większą objętość ciekłego jeziorka, jak również obniżenie napięcia powierzchniowego, co przyczynia się do większego rozpłynięcia cieczy. Z kolei wzrost prędkości napawania prowadzi do zmniejszenia szerokości powłok napawanych. Wówczas mniejsza ilość materiału dodatkowego dostarczana jest na jednostkę powierzchni co w konsekwencji doprowadza do stopniowego zmniejszania szerokości napoiny. Zarówno natężenie prądu, jak i prędkość napawania w przyjętym przedziale zmienności w sposób nieznaczny wpływają na szerokość napoin.

Wysokość nadlewu zmniejsza się zarówno gdy zwiększane jest natężenie prądu jak i prędkość napawania - rysunek 3c. Wzrost natężenia, prądu prowadzi do większego rozpływu ciekłego jeziorka, a prędkości napawania do dostarczania mniejszej ilości materiału dodatkowego

b)

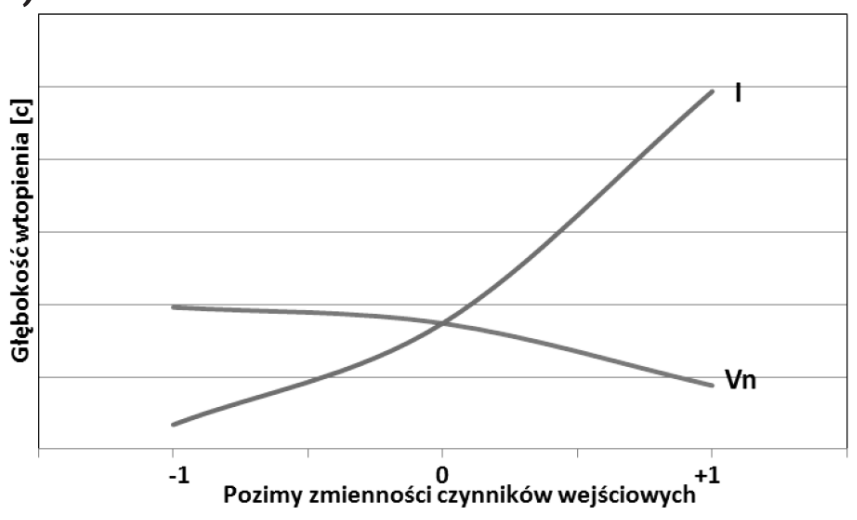

d)

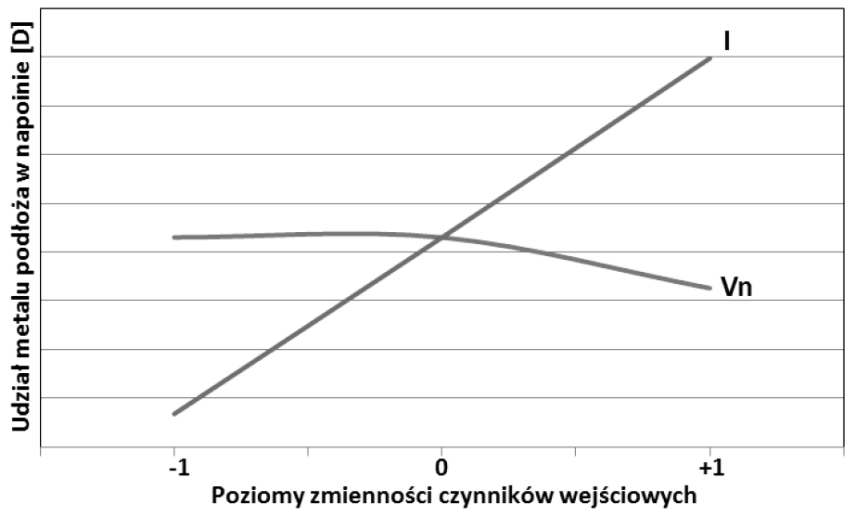

Rys. 3. Wpływ natężenia prądu i prędkości napawania na: a) szerokość napoin, b) głębokość wtopienia, c) wysokość nadlewu, d) udział metalu podłoża w napoinie

Fig. 3. The effect of welding current and speed of surfacing on: a) the width of overlay welds, b) the depth of fusion penetration, c) height of the weld reinforcement d) dilution level 
co w konsekwencji prowadzi do obniżenia wielkości nadlewu. Z rysunku 3c wynika również, iż natężenie prądu łuku głównego istotniej wpływa na wielkość nadlewu.

Tendencja zmiany głębokości wtopienia i udziału metalu podłoża w napoinie w zakresie badanych parametrów jest podobna - rysunki 3b i 3d. Wzrost natężenia prądu poprzez zwiększenie energii liniowej procesu napawania prowadzi jednocześnie do większego nadtopienia materiału podłoża oraz współczynnika wymieszania. Z kolei prędkość napawania powoduje efekt odwrotny. W początkowym zakresie wzrost prędkości napawania nie powoduje istotnych zmian głębokości wtopienia i udziału metalu podłoża w napoinie. Natomiast wzrost tego parametru powyżej pewnej wartości znacząco wpływa na mierzone wielkości. Z otrzymanych wyników badań widać także, iż rola natężenia prądu jest znacznie bardziej istotna niż prędkości napawania.

\section{Podsumowanie}

Na podstawie przeprowadzonych badań wykazano, iż natężenie prądu oraz prędkość napawania w zróżnicowany sposób wpływają na geometrię i udział metalu podłoża w napoinie. Ponadto zależności pomiędzy zmiennymi parametrami procesu a wielkościami wyjściowymi na ogół znacznie odbiegają od charakteru liniowego. Toteż otrzymane wyniki mogą stanowić wytyczne technologiczne opracowania technologii napawania dla stopu $\mathrm{Ni}$.

Statystyczne metody planowania eksperymentu stanowią cenne narzędzie zarówno w dobrze odpowiednich parametrów procesu, jak również prognozowaniu efektów napawania. Zastosowanie tych metod na etapie doboru parametrów znacząco ogranicza liczbę prób wstępnych, co wydatnie obniża czas, pracochłonność i nakłady finansowe.

\section{Literatura}

[1] Jitai N., Wei G., Mianhuan G., Shixiong L.: Plasma application in thermal processing of materials, Vacuum 65, 2002, $263-266$.

[2] Klimpel A., Górka J., Czupryński A.: Napawanie proszkowe PTA warstw wierzchnich suwaka zasuwy urządzeń naftowych, Przegląd Spawalnictwa nr $5-6,2006,15-19$.

[3] Górka J., Czupryński A., Kik T., Melcer M.: Przemysłowe aplikacje napawania plazmowego proszkowego, Przegląd Spawalnictwa nr 9, 2011, 87-94.

[4] Dewei D., Lin Z., Tingting N., Haiying L., Hongchao Z.: Microstructures and Wear Performance of PTAW Deposited Ni-Based Coatings with Spherical Tungsten Carbide, Metals, 2015, 5, 1984-1996.

[5] Wu P., Du H.M., Chen X.L., Li Z.Q., Bai H.L., Jiang E.Y.: Influence of WC particle behavior on the wear resistance properties of $\mathrm{Ni}-\mathrm{WC}$ composite coatings, Wear 257, 2004, 142-147.

[6] Yuan-Fu Liu, et al.: Microstructure and dry-sliding wear resistance of PTA clad (Cr, Fe)7C3/Y-Fe ceramal composite coating, Applied Surface Science 252, 2006, 7539-7544.

[7] Deuis R.L., Yellup J.M., Subramanian C.: Metal-matrix composite coatings by PTA surfacing. Composite Science \& Technology, 58, 1998, 299-309.

[8] Bober M. Grześ J.: The structure of Ni-TiC composite coatings deposited by PPTAW method, Composites Theory and Practice, vol. 2, 2015, 72-77.

[9] Bober M.: Composite coatings deposited by plasma transfer - characteristics and formation, Welding International, vol. 29, 2015, 946-950.

[10] Zając A., Kubiszyn I.: Analiza procesu napawania drutem proszkowym samoosłonowym Lincore 50 przy zastosowaniu metody planowania eksperymentu, Biuletyn Instytutu Spawalnictwa No 4, 1993, 35-39.

[11] Fydyrch D., Rogalski G.: Wpływ warunków spawania podwodnego metodą lokalnej komory suchej na zawartość wodoru dyfundującego w stopiwie, Przegląd Spawalnictwa No 11, 2009, 29-34.

[12] Fydrych D., Sommer S., Rogaski G.: Wspomaganie decyzji zakupu urządzeń do spawania metodą MIG/MAG z wykorzystaniem analizy skupień, Przegląd Spawalnictwa No 12, 2014, 26-33.
[13] Bęczkowski R., Gucwa M.: Statystyczna ocena wpływu parametrów napawania SSA na geometrię napoin, Przegląd Spawalnictwa No 10, 2011, 40-43.

[14] Balasubramanian V., Varahamoorthy R., Ramachandran C.S., Babu S.: Abrasive slurry wear behavior of stainless steel surface produced by plasma transferred arc hardfacing process, Surface \& Coatings Technology, 202, 2008, 3903-3912.

[15] Ramachandran C.S., Balasubramanian V., Varahamoorthy R.: Comparative evaluation of dry sliding wear behaviour of plasma transferred arc hardfaced surfaces by the pin-on-roller method, Proc. IMechE Vol. 224 Part J: J. Engineering Tribology, 2010, 91-106.

[16] Siva K., Murugan N., Logesh R.: Optimization of weld bead geometry in plasma transferred arc hardfaced austenitic stainless steel plates using genetic algorithm, Int J Adv Manuf Technol, vol. 41, 2009, 24-30.

[17] Lakshminarayanan A. K., Balasubramanian V., Varahamoorthy R., Babu S.: Predicting the Dilution of Plasma Transferred Arc Hardfacing of Stellite on Carbon Steel Using Response Surface Methodology, METALS AND MATERIALS International, Vol. 14, No. 6, 2008, 779-789.

[18] Bęczkowski R.: Effect of cladding parameters on the hardness of bimetal plates, Metalurgija, 56, 2017, 1-2, 59-62.

[19] Bober M., Tobota K.: Badania istotności wpływu podstawowych parametrów napawania plazmowego na geometrię napoin, Przegląd Spawalnictwa, No 9, 2015, 24-28.

[20] Klimpel A.: Technologie napawania i natryskiwania cieplnego, wyd. Pol. Śląska, Gliwice 1999.

[21] Bober M., Senkara J.: Wpływ podstawowych parametrów napawania plazmowego na udział metalu podłoża w napoinie kompozytowej, Sympozjum Katedr i Zakładów Spawalnictwa, Gliwice, 10.X.2003r, Materiały konferencyjne, 51-60.

[22] Bober M., Senkara J.: Formowanie się napoin na bazie niklu z węglikami metali przejściowych, Biuletyn Instytutu Spawalnictwa, nr 5/2010, rocznik 54, 103-107.

[23] Korzyński M.: Metodyka eksperymentu, WNT, Warszawa 2006.

\section{Zapraszamy Państwa do odwiedzenia i polubienia naszego profilu na Facebooku}

